Original Research

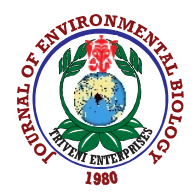

DOI : http://doi.org/10.22438/jeb/41/2/MRN-1034
Journal Home page : www.jeb.co.in $\star$ E-mail : editor@jeb.co.in

Journal of Environmental Biology

$\mathrm{JEB}$

p-ISSN: 0254-8704

e-ISSN: 2394-0379

CODEN: JEBIDP

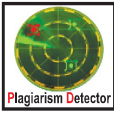

White Smoke

\title{
Assessment of genetic variability of chilli in Western Himalayan Region
}

\author{
S.R. Singh ${ }^{1 *}$, N. Ahmed', D. Kumar', A.K.Trivedi ${ }^{2}$, A. Singh ${ }^{2}$ and M. Mir ${ }^{1}$ \\ 'Crop Improvement Division, ICAR- Central Institute of Temperate Horticulture, Rangregth-190 007, India \\ ${ }^{2}$ Crop Production Division, ICAR- Central Institute for Subtropical Horticulture, Lucknow-226 101, India
}

*Corresponding Author Email : srajparmar@gmail.com

\section{Abstract}

Aim : The present study was conducted with the aim to collect and evaluate the available genetic diversity of chilli (Capsicum annuum L.) in order to identify promising accessions for cultivation as well as use in crop improvement.

Methodology : A total 78 accessions of chilli were collected from Western himalayan region, i.e., Kashmir valley of India. Collected germplasm was evaluated at one location for fifteen quantitative traits of horticultural importance.

Results : With ample diversity in these traits, a high coefficient of variation was found. Principal Component Analysis (PCA) revealed that first five principal components possessed eigen value $>1$, cumulatively contributed $>65.2$ percent of total variability. All the genotypes were grouped into five clusters showing non parallelism between geographic and genetic diversity.

Interpretation: The genotypes grouped in different clusters may be utilized for hybridization programme to produce more heterotic recombinants.

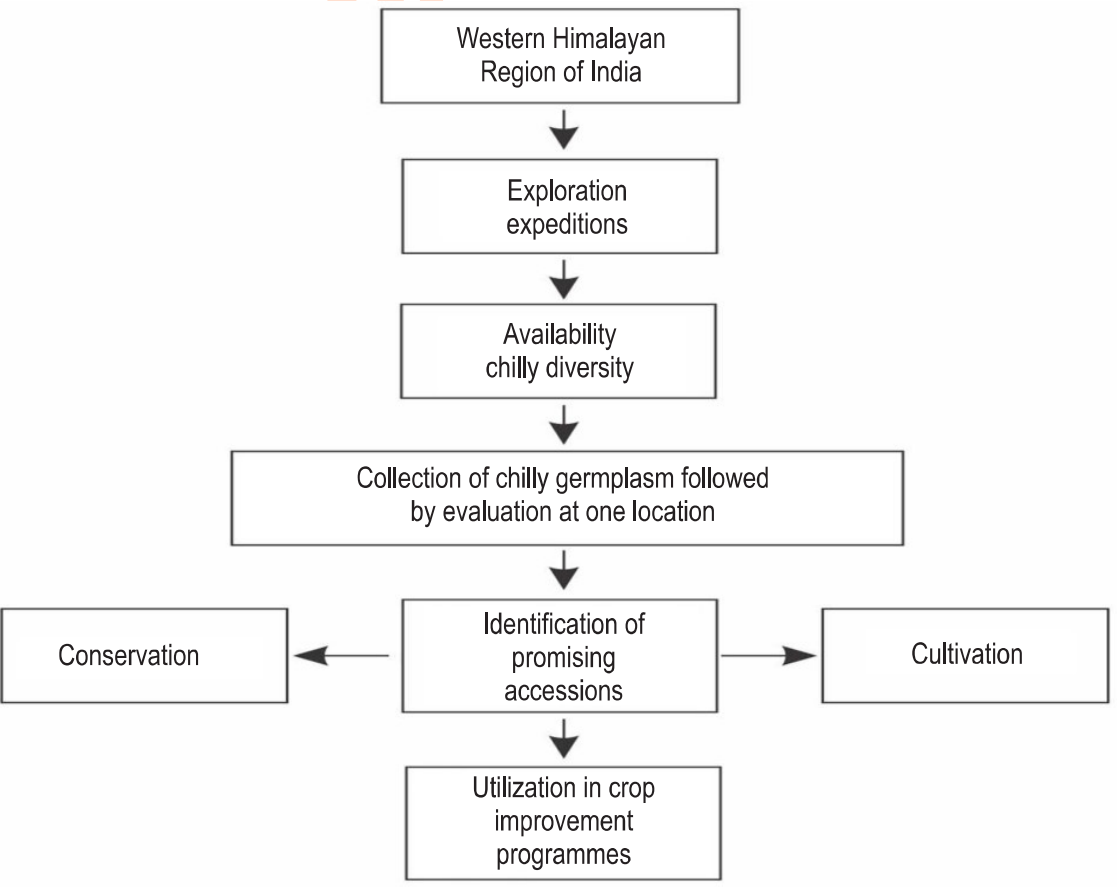

Key words: Capsicum annuum, Genetic variability, Germplasm, Single linkage cluster analysis

How to cite : Singh, S.R., N. Ahmed, D. Kumar, A.K. Trivedi, A. Singh and M. Mir: Assessment of genetic variability of chilli in Western Himalayan Region J. Environ. Biol., 41, 266-273 (2020). 


\section{Introduction}

Chilli (Capsicum annuum L.) is an important vegetable and spice crop (Bozokalfa et al., 2009). The wide genetic diversity for phenotypic as well as horticultural traits make Capsicum annuum globally important for culinary (cooked vegetable, food ingredient, colorant), cosmetics and medicinal use (Andrews. 1999; Bosland and Votawa, 2000). India is the largest producer of chilli in the world and has the highest per capita consumption among all spices produced in the country. It is used as an essential condiment in food for its pungency and red colour (Woodburry, 1997). Chilli imparts appealing colour, aesthetic flavour and aroma, has many end uses in different food, pharmaceutical and cosmetic preparations (Prasath et al., 2007). The indiscriminate use of synthetic colours in the food has several harmful effects on human health (Saleem et al., 2013). This has resulted in huge demand for chilli with high colorant and mild pungency. Western Himalayan Region i.e., Kashmir Valley of India is known for rich coloured chilli with large variability in plant morphology and fruit shape, size and colour (Singh et al., 2014). Chilli is either sold as whole or in the processed powder form.

The external quality traits such as fruit size, homogeneity in colour and brightness influence consumer preference. Generally, long fruit with medium pericarp thickness having intense colour is preferred by consumers as well as processing industries. In fact, colour of chilli decides its price in the market. Hence, it is crucial to evaluate the available germplasm for these traits and identification of parents for genetic restructuring of chilli for high colour and yield. Precise information on the nature and degree of genetic diversity helps a plant breeder to select diverse parents for purposeful hybridization (Samsuddin, 1985). Genetically diverse parents in any breeding programme are of immense importance for successful recombination breeding (Arunachalam, 1981). For an effective breeding program for crop variety development through hybridization, the analysis of genetic diversity is one of the useful tools and plays a fundamental role in identification of parents (Mazid et al., 2013). Moreover, better knowledge on genetic diversity can help to achieve long-term selection gain (Chowdhury, 2002).

As a traditional method, morphological traits are used to assess genetic divergence and classify existing germplasm materials (Malek et al., 2014). Numerical taxonomic techniques have also been used by many workers to classify variation patterns at both intra and inter specific level (Sneath and Sokal, 1973; Ariyo and Odulaja, 1991). Kashmiri chilly is used as colouring material for garnishing food material. In breeding no such high colouring genotype has been identified which can be recommended for commercial extractions of colour content to spice industry and pharmaceutical companies. In Kashmiri chilly, rich genetic diversity in colour content has been found. Thus, it is crucial to assess the germplasm having high colour content and yield to improve the chilly breeding program. The genetic stocks with high colour content and good yield will be useful for production of natural colour (oleoresin colour) content by spice industry. Thus, the present investigation was carried out to capture the potential of genetic diversity in chilli germplasm by using multivariate analytical techniques and selection of suitable parents for future crop improvement programme.

\section{Materials and Methods}

A total 78 accessions of Capsicum annum were collected from Western Himalayan Region, i.e., Kashmir Valley of India (Table 1). Experiment was conducted in randomize block design (RBD) with three replications having two rows. Twenty plants were maintained in each replication. The seeds were sown in poly house in the mid of March and transplanted in open field in the mid of May at $60 \times 45 \mathrm{~cm}$ spacing. Standard agronomic practices were followed uniformly to allow each plant of the plot for full expression of the characters. The data were collected from 10 plants randomly. The morphological traits viz, plant height, fruit length, fruit diameter, fruit weight, number of seeds/ fruit, number of fruits/ plant and fruit yield/ plant were recorded at experimental site following standard procedures, while surface colour ( $L, A, B$, Hue and Croma) was measured by Hunter Colour Lab (Colour Flex EZ's $45^{\circ} / 0^{\circ}$ design). The extractable colour was determined according to AOAC (1995) procedure.

Data collected based on the quantitative characters were analyzed using SAS Microsoft Windows 9.2 (SAS Institute, 2011), employing the method outlined by Steel and Torrie (1980). Genetic diversity was studied following Mahalanobis's (1949) generalized distance $\left(D^{2}\right)$ extended by Rao (1952). Average intracluster distance was calculated by the formula given by Singh and Choudhary (1985). Principal Component Ananlysis and single linkage cluster analysis (SLCA) was used for the determination of genetic variation and percentage similarity within genotypes. PCA produced eigen-vectors and principal components scores that were used to measure the relative discriminative power of the axes and their associated characters respectively (Hayman, 1967). Cluster analysis was done to produce distinct groups of 78 genotypes on the basis of genetic relationship using character variation. Single cluster linkage summarized the position of accessions in a dendogram at an interval of $5 \%$ dissimilarity level.

\section{Results and Discussion}

Among the collected germplasm, considerable variability was found in all the traits under study (Table 2). Coefficient of variation for different traits ranged from 50.75 to 3.05 . The highest coefficient of variation was observed for fruit surface colour $(50.75 \%)$, followed by number of fruits /plant $(49.68 \%)$, hue $(45.52 \%)$ and average fruit weight $(42.93 \%)$. Wide range of variability was observed in different traits viz., fruit yield/ plant (48.19 - $962.69 \mathrm{~g})$, number of fruits/ plant (12.66 - 225.00), plant height $(49.00-99.63 \mathrm{~cm})$ and spread $(33.66-73.66 \mathrm{~cm})$.

The maximum fruit yield/ plant $(956.54 \mathrm{~g})$ was found in the genotype CITH-1056/52, followed by genotype CITH-1025-11 $(833.04 \mathrm{~g})$. The maximum fruit number/ plant (225) was recorded 
Table 1: Area/ location of chilli (Capsicum annuum L.) germplasm collection in the Western Himalayan Region in Jammu and Kashmir, India

\begin{tabular}{|c|c|c|}
\hline Districts explored & Location of germplasm collection & Number of accessions collected \\
\hline Srinagar & Noorbag, Saibook, Shalimar, & $\begin{array}{l}\text { SH-HP-1154-5-1,SH-HP-1154-4, SH-HP-1154-4-3, SH-HP-1154-1, SH- } \\
\text { HP-1154-8-2, SH-HP-1154-8-1 SH-HP-1154-9-2, KC-12-1,KL-Sel-2, KC- } \\
\text { 12,SH-KC-12-1,KC-1-1,SH-KC-12,SH-HP-7-1,C/S 07/11, CITH-813-1- } \\
\text { 2,CITH-1016-1.CITH-1056-2, CITH-AL-1,CITH-S-3, CITH-1154--4- } \\
\text { 3,CITH-1008-1-1 }\end{array}$ \\
\hline Pulwama & Narbal, Bhogam & $\begin{array}{l}\text { CITH-917-1-1,CITH-839-2, CITH-1051/11-1,CITH-1154-1-2, CITH-1154- } \\
\text { 9-2, CITH-839-2-1, , CITH-839-1-2, CITH-1008-1-1, , CITH-836-1, , CITH- } \\
\text { Selc-2,CITH-1050/11, CITH-836-1-2, CITH-2011-5-2, , CITH-839-2, , CITH- } \\
\text { 8-2-6-2, , CITH-836-2, , CITH-836-2, , CITH-C-S-7 }\end{array}$ \\
\hline Budgam & Latipora Mogam & $\begin{array}{l}\text { CITH-1008-1-1, , CITH-Al-5-1, CITH-2011-5-2, (self), CITH-1002-1-3, } \\
\text { CITH-2011-4, CITH-942-1, CITH-1016, CITH-89-1, CITH-1009-11, CITH- } \\
\text { 140-1 CITH-1012, CITH-1055/11-1,CITH-AL-6,CITH-AL-3, ,CITH-AL-4, } \\
\text { CITH-AL-5,CITH-1052-1,CITH-1052-1, ,CITH-1065-1,CITH-Al-2,CITH- } \\
\text { AL-7, ,CITH-1054-6-1,,CITH-1056/2,CITH-888-2, CITH-C-S-6,CITH-910- } \\
\text { 1-1, CITH-1056/2,CITH-1005/11-1,CITH-910-1-1CITH-Al-7-2,CITH-1016- } \\
\text { 4,CITH-1056/S-2 }\end{array}$ \\
\hline
\end{tabular}

Table 2 : Variability in morphological and colour attributing traits of chilli (Capsicum annuum L.) germplasm from Western Himalayan Region in Jammu and Kashmir, India in terms of range, mean, standard deviation and covariance

\begin{tabular}{llllll}
\hline Parameters & \multicolumn{2}{l}{ Range } & Mean & Std & CV (\%) \\
\cline { 2 - 3 } & Min & Max & & & 16.01 \\
\hline Plant height $(\mathrm{cm})$ & 49.00 & 99.33 & 74.17 & 12.33 & 16.56 \\
Plant spread (cm) & 33.66 & 73.66 & 53.66 & 8.60 & 13.69 \\
No of branches/plant & 4.66 & 7.66 & 6.16 & 0.85 & 49.68 \\
No of fruits/plants & 12.66 & 225.00 & 118.83 & 52.13 & 31.68 \\
Fruit length (mm) & 11.20 & 38.51 & 24.86 & 5.04 & 42.43 \\
Fruit diameter (mm) & 3.02 & 16.20 & 9.61 & 2.97 & 42.38 \\
Average fruit weight (g) & 2.00 & 13.53 & 7.77 & 2.42 & 28.93 \\
Fruit yield/plant (g) & 48.19 & 962.69 & 505.44 & 218.28 & 3.05 \\
No. of seed /fruit & 55.66 & 149.33 & 102.50 & 23.91 & 21.28 \\
L & 30.04 & 34.69 & 32.37 & 0.95 & 50.75 \\
A & 0.44 & 4.64 & 2.54 & 0.90 & 45.62 \\
B & 0.27 & 3.24 & 1.76 & 0.68 & 33.95 \\
Hue & 10.20 & 74.97 & 42.59 & 14.58 & 21.51 \\
Croma & 1.44 & 7.84 & 4.64 & 0.92 & 19.54 \\
ASTA & 38.28 & 130.15 & 84.22 & & \\
\hline
\end{tabular}

in SH-HP-1154-9-2. The maximum fruit length $(132.31 \mathrm{~mm})$ was observed in $\mathrm{CITH}-1056-2$. The maximum extractable colour (130.15 ASTA) and surface colour (A) (34.49) was recorded in CITH-1054-6-1 and KC-12-1, respectively. These findings are in confirmation with the findings of Udachappa et al. (2017).

Principal component analysis revealed that five principal components (PC-I - PC-V) had eigen values > 1 and cumulatively accounted for $65.2 \%$ of total variation (Table 3 ). The first principal component (PC-I) explained $19.40 \%$ of total variability and traits positively contributing towards first component were fruit weight (0.493), fruit diameter $(0.407)$ and fruit length (0.287). Extractable colour (ASTA) (0.429), croma (0.424), fruit yield/ plant (0.458), number of fruits/ plant (0.369), plant spread (0.338) and surface red colour (0.336) were found to be the main traits contributing towards PC-II, which were responsible for $15.40 \%$ of total variability. The traits positively contributing towards PC-III were plant height $(0.333)$ and hue of fruits $(0.637)$ which were responsible for $13 \%$ of total variability. The principal component-IV was responsible for $9.9 \%$ variation, 


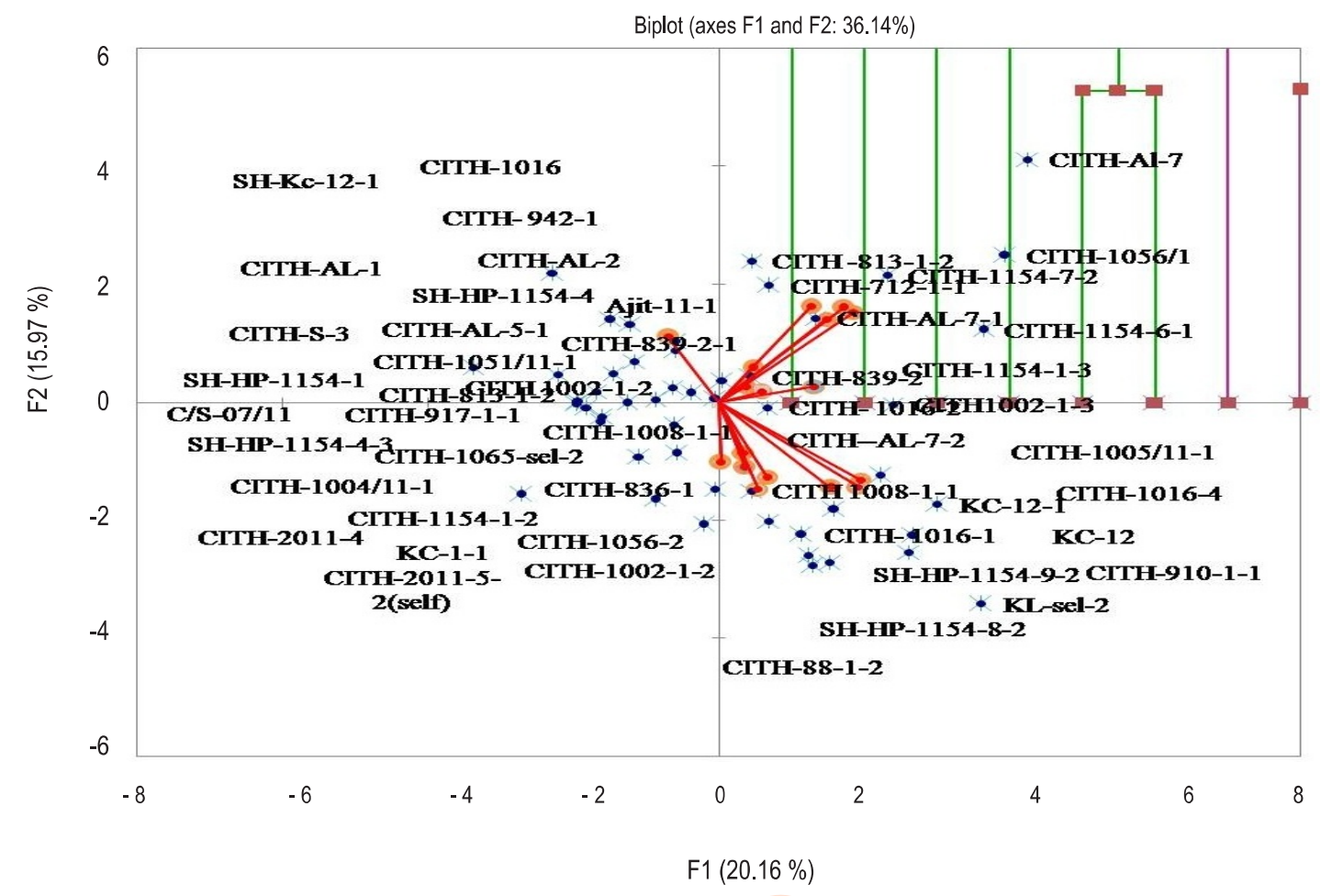

Fig. 1: Biplot for $1^{\text {st }}$ and $2^{\text {nd }}$ PC for 16 horticultural traits in 78 genotype of chilli (Capsicum annuum L.) germplasm from Western Himalayan Region in Jammu and Kashmir, India.

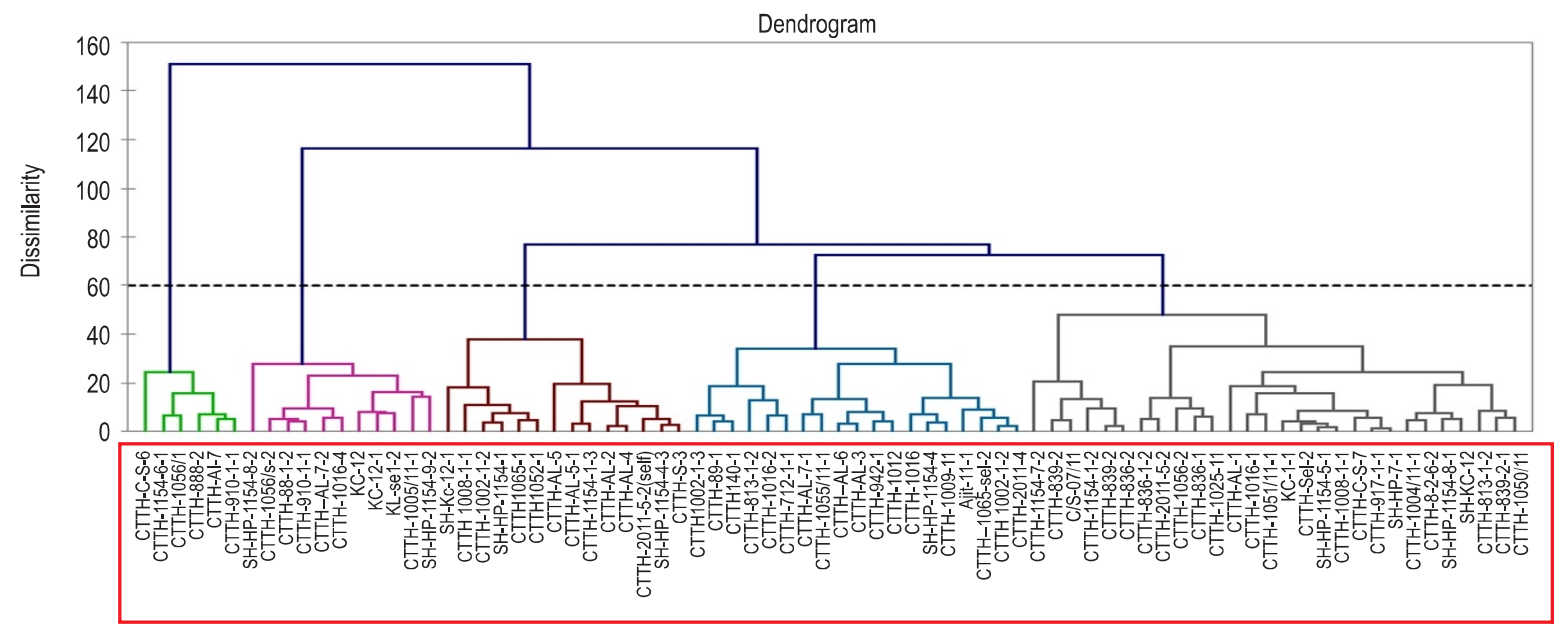

Fig. 2: Dendogram depicting genetic relationships among 78 chilli (Capsicum annuum L.) germplasm from Western Himalayan Region in Jammu and Kashmir, India based on horticultural traits produced by complete linkage analysis (Scale-Euclidean distance).

and the positively contributing traits were number of branches/ plant (0.368) and number of seed/ fruit (0.290) whereas principal component $V$ accounted for $7.6 \%$ of total variability, responsible traits were plant height $(0.260)$ and brightness of fruit colour 
Table 3 : Latent vector for Eigen values and proportion of variance by different components with respect of different traits of chilli (Capsicum annuum L.) germplasm from Western Himalayan Region in Jammu and Kashmir, India

\begin{tabular}{llllll}
\hline Characters & I & II & III & IV & V \\
\hline Plant height(cm) & 0.112 & 0.082 & 0.333 & 0.004 & 0.260 \\
Plant spread (cm) & 0.035 & 0.338 & 0.194 & 0.197 & 0.279 \\
Number of braches & -0.060 & 0.259 & 0.006 & 0.368 & 0.362 \\
Number of fruit /plant & 0.016 & 0.369 & 0.106 & 0.379 & -0.039 \\
Fruit length (mm) & 0.287 & 0.119 & 0.084 & -0.056 & -0.394 \\
Fruit diameter (mm) & 0.407 & -0.125 & -0.087 & 0.037 & 0.074 \\
Fruit weight (g) & 0.493 & 0.096 & 0.035 & 0.077 & 0.052 \\
Fruit yield/plant & 0.021 & 0.458 & 0.089 & 0.256 & -0.046 \\
No of seeds /fruit & 0.149 & -0.043 & 0.014 & 0.290 & -0.550 \\
L & 0.017 & 0.248 & -0.243 & -0.384 & 0.319 \\
A & 0.215 & 0.336 & -0.285 & -0.254 & -0.141 \\
B & 0.138 & 0.122 & 0.507 & 0.379 & -0.079 \\
Hue & -0.006 & -0.106 & 0.637 & -0.146 & 0.012 \\
Croma & 0.183 & 0.424 & -0.098 & -0.330 & -0.046 \\
Extractable colour (ASTA) & 0.123 & 0.429 & -0.095 & -0.34 & 0.042 \\
Eigen value & 3.097 & 2.459 & 2.048 & 1.585 & 1.209 \\
Proportion of variance & 19.40 & 15.40 & 13.00 & 9.90 & 7.60 \\
Cumulative variance & 19.40 & 34.80 & 47.80 & 57.70 & 65.20 \\
\hline
\end{tabular}

(0.319). The bi-plotting of PC-I and PC-II showed considerable variability with dispersion pattern of delineated genotypes (Fig.1). All genotypes having negative values for PC-I and PC-II were dwarf in nature, shorter type of fruit, lower fruit weight, minimum branches and lower yield but had better extractable colour. Genotypes having positive values for PC-I and PC-II had larger size of plants, more number of branches, larger size of fruits with maximum fruits/ plant and higher fruit yield. Genotypes having positive value for $\mathrm{PC}$-I but negative values for $\mathrm{PC}$ - II had medium type of plants with higher number of long fruits with low fruit diameter and higher yield and better surface and extractable colour. Genotypes SH-KC-12.1, CITH-AL-7, KL-Sel-2, CITH1556/1 and CITH-15556-2 were found to be the most divergent genotypes for important horticultural traits viz., fruit size colour and yield (Fig. 2).

Traits which are positively, contributing towards PC-I to $\mathrm{PC}-\mathrm{V}$ are important because these axes explain more than $65.2 \%$ of total variability. Higher contributing characters viz., fruit weight, fruit length, fruit diameter, number of fruit/ plant, fruit yield/ plant, fruit surface colour, plant height and number of branches indicated their importance and could be taken into account while selecting the best parents for hybridization or direct selection without losing the yield and quality traits. Similar findings were earlier reported by Ahmed et al. (2014), Singh et al. (2013b) and Nahak et al. (2018) in brinjal, onion and chilli, respectively. PCA has also been used for studying genetic variability in germplasm collection of different species (Ahmed et al., 2014; Singh et al., 2013a, Bhargava et al., 2007). Genotypes namely SH-KC-12. 1, CITH, AL-1, CITH-AL-7, KL-Sel-2, CITH-1556/1 and CITH-15556-2 were most divergent as observed in the dendogram depicting genetic relationships among 78 chilli genotypes based on horticultural traits produced by complete linkage analysis (Fig. 2). These diverse genotypes may be employed as distinct parents in the future breeding programme, especially in hybridization.

Single linkage cluster analysis showed that all the genotypes group in five cluster identifying the share of genotypes and cluster means of all traits (Table 4). The maximum number of genotypes were accommodated in cluster - I (28), followed by cluster - II (19), cluster - III (14), cluster - V (11) and minimum in cluster - IV (6) contributing $36,24,18,14$ and $8 \%$ share of total evaluated population, respectively. On the cluster mean basis, the most important cluster was cluster - I, for number of fruits/ plant (94.41), surface fruit colour (A) (2.44) and extractable colour (ASTA) (95.34). Similarly, cluster- II was important for plant height (81.84), fruit yield/ plant (121.22) and number of seeds/ fruits. Cluster - III was important for fruit croma (2.79), cluster IV for plant spread (53.35), fruit length (18.84), fruit diameter (8), average fruit weight (6.73) and lustiness of fruit (31.32) whereas cluster $V$ was important for number of branches (6.34) and fruit yield /plant (116.11). On the basis of characters and their relative positions in different clusters there was a clear grouping among the genotypes. The highest mean cluster for specific traits can be utilized for genetic restructuring of chilli for a particular trait.

The highest inter cluster distance between cluster IV and cluster V (76.93), followed by cluster III and cluster V (59.54) was obvious by high degree of divergence between the genotypes of these clusters. Kumar et al. (2010) elucidated that hybrids of genotypes with maximum cluster distance resulted higher heterosis in yield and thus cross between the genotypes of cluster IV and V as well as cluster III and V can be used in chilli breeding for maximum heterosis, and isolating useful recombinants in segregating generations as well as for introgressing their useful traits in commercial chilli cultivars. The 
Table 4: Cluster means for characters along with genotypes distribution of respective cluster of chilli (Capsicum annuum L.) germplasm from Western Himalayan Region in Jammu and Kashmir, India

\begin{tabular}{|c|c|c|c|c|c|c|}
\hline \multirow[t]{2}{*}{ S.No } & \multirow[t]{2}{*}{ Characters } & \multicolumn{5}{|c|}{ Clusters (No. of entries with code and \% share of genotype) } \\
\hline & & I & II & III & IV & V \\
\hline & & $28(36 \%)$ & $19(24 \%)$ & $14(18 \%)$ & $6(8 \%)$ & $11(14 \%)$ \\
\hline 1. & Plant height $(\mathrm{cm})$ & 74.78 & 81.84 & 77.66 & 75.24 & 76.76 \\
\hline 2. & Plant Spread (cm) & 51.23 & 53.10 & 51.68 & 53.35 & 51.19 \\
\hline 3. & No of branches/plant & 5.89 & 6.02 & 5.51 & 6.24 & 6.34 \\
\hline 4. & No of fruits/plants & 94.41 & 88.26 & 84.93 & 92.64 & 89.04 \\
\hline 5. & Fruit length $(\mathrm{mm})$ & 16.89 & 14.56 & 14.68 & 18.84 & 15.13 \\
\hline 6. & Fruit diameter(mm) & 7.04 & 6.50 & 6.27 & 8.00 & 7.25 \\
\hline 7. & Ave. Fruit weight (g) & 5.88 & 4.99 & 5.76 & 6.73 & 5.63 \\
\hline 8. & Fruit yield/plant (g) & 98.35 & 121.22 & 94.26 & 93.60 & 116.11 \\
\hline 9. & No. of seed /fruit & 85.54 & 104.02 & 78.22 & 84.49 & 77.36 \\
\hline 10. & L & 31.13 & 30.70 & 31.19 & 31.32 & 31.24 \\
\hline 11. & $A$ & 2.44 & 1.85 & 1.98 & 2.02 & 2.39 \\
\hline 12. & B & 1.43 & 1.33 & 1.21 & 1.39 & 1.27 \\
\hline 13. & Hue & 30.30 & 39.42 & 31.72 & 32.91 & 28.82 \\
\hline 14. & Croma & 2.79 & 2.50 & 2.80 & 2.69 & 2.72 \\
\hline \multirow[t]{29}{*}{15.} & ASTA & 95.34 & 83.90 & 87.00 & 89.98 & 94.74 \\
\hline & & SH-HP-1154-5-1 & CITH 1002-1-2 & CITH 1008-1-1 & ClTH-Al-7 & KC-12-1 \\
\hline & & CITH-813-1-2 & SH-HP-1154-4 & SH-Kc-12-1 & CITH-1154-6-1 & KL-sel-2 \\
\hline & & CITH- 1016-1 & CITH -813-1-2 & CITH-AL-5-1 & ClTH-1056/2 & CITH-88-1-2 \\
\hline & & CITH-1056-2 & CITH- 1016-2 & CITH-2011-5-2(self) & CITH-888-2 & KC-12 \\
\hline & & CITH-004/11-1 & CITH-AL-7-1 & CITH-1002-1-2 & CITH-C-S-6 & CITH-1005/11-1 \\
\hline & & CITH-917-1-1 & CITH-712-1-1 & SH-HP-1154-4-3 & CITH-910-1-1 & CITH-910-1-1 \\
\hline & & ClTH-839-2 & Ajit-11-1 & SH-HP-1154-1 & & CITH--AL-7-2 \\
\hline & & CITH-1051/11-1 & CITH-1065-sel-2 & CITH-1154-1-3 & & SH-HP-1154-9-2 \\
\hline & & CITH-1154-9-2 & CITH1002-1-3 & CITH-S-3 & & ClTH-1016-4 \\
\hline & & CITH-1154-1-2 & CITH-2011-4 & CITH-AL-2 & & SH-HP-1154-8-2 \\
\hline & & CITH-839-2-1 & CITH- 942-1 & CITH1065-1 & & ClTH-1056/s-2 \\
\hline & & C/S-07/11 & CITH-1016 & CITH1052-1 & & \\
\hline & & CITH-1008-1-1 & CITH-89-1 & CITH-AL-5 & & \\
\hline & & $\mathrm{KC}-1-1$ & CITH-1009-11 & CITH-AL-4 & & \\
\hline & & CITH-AL-1 & CITH140-1 & & & \\
\hline & & CITH-836-1 & CITH-1012 & & & \\
\hline & & ClTH-Sel-2 & CITH-1055/11-1 & & & \\
\hline & & ClTH-1050/11 & CITH-AL-6 & & & \\
\hline & & CITH-1025-11 & CITH-AL-3 & & & \\
\hline & & CITH-836-1-2 & & & & \\
\hline & & CITH-2011-5-2 & & & & \\
\hline & & SH-HP-1154-8-1 & & & & \\
\hline & & SH-KC-12 & & & & \\
\hline & & CITH-839-2 & & & & \\
\hline & & CITH-8-2-6-2 & & & & \\
\hline & & ClTH-836-2 & & & & \\
\hline & & CITH- C-S-7 & & & & \\
\hline & & SH-HP-7-1 & & & & \\
\hline
\end{tabular}

minimum distance between the genotypes of cluster-I and cluster-III can be used for back crossing programme. The investigators reported high genetic divergence in chilli genotypes and cluster analysis can be useful for finding high yielding better coloured genotypes (Tasso et al., 2014; Mishra et al., 2004).
This method has an added advantage over other criteria permitting precise comparison among all the possible pairs of population in any group. Crop improvement is made through generating variability in desired traits followed by selection. Continued success in varietal improvement can only be realized 
Table 5: Average intra (bold face) and inter cluster distances $\left(D^{2}\right)$ of 78 genotypes of chilli (Capsicum annuum L.) germplasm from Western Himalayan Region in Jammu and Kashmir, India

\begin{tabular}{llllll}
\hline & $\mathbf{1}$ & $\mathbf{2}$ & $\mathbf{3}$ & $\mathbf{4}$ & $\mathbf{5}$ \\
\hline 1 & 0 & 27.48 & 8.27 & 55.56 & 21.37 \\
2 & 0 & 0.79 & 28.08 & 48.85 \\
3 & & 0 & 17.29 & 59.64 \\
4 & & & 0 & 76.93 \\
5 & & & & 0 \\
\hline
\end{tabular}

Table 6: Accessions selected for best horticultural traits of interest in chilli (Capsicum annuum L.) germplasm from Western Himalayan Region in Jammu and Kashmir, India

\begin{tabular}{lll}
\hline Traits of interest & Selection criteria & Genotypes/accessions \\
\hline Number fruits/plant & $>150$ & CITH-1051-1, CITH-910-1-1,SH-SP1154-9-2,CITH-1002-1-3,CITH-89-1,SH-KC-12 \\
Fruit length & $>100 \mathrm{~mm}$ & CITH-813-1-2,CITH-1016-2,CITH-AL-7-1,CITH-712-1-1,SH-HP-1054-9-2CITH-1056/S-2 \\
Fruit yield/plant & $>825 \mathrm{~g}$ & CITH-1065/S-2, CITH-1052-1,CITH-1025-11 \\
Fruit lustiness (L value) & $>32$ & CITH-102-1-2, CITH-1016-1, CITH-910-1-1CITH-1016-4 \\
Extractable colour (ASTA) & $>100$ & CITH-1054-6-1,CITH-1016-1,CITH-1005-11-1,CITH-910-1-1 \\
\hline
\end{tabular}

when new substantial variability is used in a population (Tasso et al., 2014). Genotypes grouped in same cluster presumably diverge very little from one another and do not produce desirable segregants when used as parents for hybridization (Roy et al., 2013). Hence, hybridization programme should be initiated with putative parents belonging to different characters. Therefore, parents with higher inter cluster distance are likely to be beneficial for further improvement in chilli. Genotypes identified on the basis of performance of desirable horticultural traits may be used for improvement of chilli viz., CITH-1051-1 and CITH-90-1-1 for number of fruits per plant, $\mathrm{CITH}-813-1-2$ and $\mathrm{CITH}-1016-2$ for fruit length, $\mathrm{CITH}-1065 / \mathrm{S}-2$ and $\mathrm{CITH}-1052-1$ for fruit yield/ plant, CITH-102-1-2 and CITH-1016-1 for fruit lustiness and more importantly CITH-1054-6-1 and CITH-1016-1 for extractable colour. Many of them are better for more than one trait and may be used as such to reduce varietal development span (Azmat et al., 2011). Dendogram drawn from SLCA shows relationship between 78 genotypes (Fig. 2). All the genotypes were distinct from each other at $100 \%$ level of similarity whereas formed 12 clusters at $20 \%$ level of similarity and four clusters at $80 \%$ of similarity. The genotype CITH-1050/11, CITH-C-5-6, SH-HP-1154-8.2, CITH AL-5, CITH-1002-1-3, CITH-1154-4, CITH-AL-1 were found to be the most divergent parents. It indicates that these genotypes have distant parents. The non-hierarchical cluster analysis values in the present study showed maximum inter cluster distance existed between cluster -IV and cluster -V (76.93), followed by cluster III and cluster V (59.54) which indicates that genotypes of these clusters were genetically divergent whereas, minimum inter cluster distance was observed between cluster-I and cluster-III (0.79), which indicates that the genotypes of these clusters were genetically close to each other (Table 5).
On the basis of performance with respect to desirable horticultural traits, genotypes were identified and presented in Table 6 . Six genotypes produced $>150$ fruits/ plant, 6 genotypes produced $>100 \mathrm{~mm}$ fruit length, 3 genotypes produced $>825 \mathrm{~g}$ fruit /plant, 4 genotype produced $32 \mathrm{~L}$ of fruit lustiness and 6 genotypes produced > 100 ASTA extractable colour (Table 6). High coefficient of variation was observed for surface colour, number of fruits /plant, hue and average fruit weight. Wide range of variation was observed for fruit yield/ plant, number of fruits/ plant, plant height, plant spread and number of seeds/ fruit whereas minimum range of variability was observed for fresh seed weight/ fruit. High coefficient of variation and wide range of quantitative characters confirm high degree of variability for assessed traits. Genotype CITH1056/5-2, CITH-1025-11, SHHP-1154-9-2, CITH-1056-2, Cith-1054-6-1 and KC-12-1 were found most divergent for yield, number of fruit/ plant, larger fruit size and colour intensity, respectively.

These findings are in agreement with the earlier reports of Tasso et al. (2014) and Raihana et al. (2019), who reported wide range of variability in chilli plant morphology, fruit size and colour. Difference among the individuals of population is an indication of diversity (Azmat et al., 2011), and existence of variability is critical for crop improvement programme. Magnitude of variability for specific character determines the success of genetic improvement of particular character (Sharma et al., 2003). Hence, it may be concluded that a wide range of variability among all the economically important traits is available in selected genotypes. This implies ample potential for breeding through hybridization or may be used directly as a variety for successful chilli production with high colour content. 


\section{Acknowledgment}

Authors are thankful to the Director, ICAR- Central Institute of Temperate Horticulture, J \& K (India) for providing necessary facilities and keen interest in the study.

\section{References}

A.O.A.C.: Official Methods of Analysis. Association of Official Analytical Chemists, 43.1.02. (971.26), Washington DC (1995).

Ahmed, N., S.R. Singh, S. Lal, K.A. Mir, A. Asima, K. Habib and M. Salmani: Assessment of genetic diversity in brinjal (Solanum melongena L.) genotypes using multivariate analysis. Ind. J. Hort., 71, 494-498 (2014).

Ariyo, O.J. and A. Odulaza: Numerical analysis of variation among accessions of okra. (A. esculentus L. Moench). Malvaceae. Ann. Bot., 67, 527-531 (1991).

Arunachalam, G.: Genetic distances in plant breeding. Ind. J. Genet., 41, 226-236 (1981)

Azmat, M. A., N.N. Nausherwan, A.K. Asif, M. Ashraf, N. Shahid and M. Khalid : Characterization of pea germ Plasm. Int. J. Veg. Sci., 17, 246-258 (2011).

Andrews, J.: The pepper trial: History and recipes from around the world . University of North Texas Press Denton Texas USA (1999).

Bhargava, A., S. Shukla, S. Rajan and D. Ohri: Genetic diversity for morphological and quality traits in quinoa (Chenopodium quinoa Wild) germplasm. Genet. Resour. Crop Evol., 54, 167-73 (2007).

Bosland, P.W. and E.J. Votawa: Peppers: Vegetable and Spices Capsicums. CABI Publishing Oxon UK and New York (2000).

Bozokalfa, M.K., D. Egiyok and K. Tarun: Patterns of phenotypic variation in a germplasm collection pepper (Capsicum annuum L.) from Turkey. Spanish J. Agric. Sci., 7, 83-95 (2009).

Chowdhury, M.A., B. Vandenberg and T. Warkentin: Cultivar identification and genetic relationship among selected breeding lines and cultivars in chickpea (Cicer arietinum L.). Euphytica, 127, 317-325 (2002).

Hayman, H. H.: Modern Factor Analysis. $2^{\text {nd }}$ Edn., University of Chicago Press, Chicago., p. 474 (1967)

Kumar, B., M. Kantti and D. Malikarjunaiah : Genetic divergence in chilli accessions. Electronic J. Plant Breed.,1, 1363-1366 (2010).

Mahalanobis, P. C.: On the generalized distance in statistics. Proc. Natl. Acad. Sci., 2, 49-55(1936).

Malek, M.A., M.Y. Rafii, M. S.S. Afroz, U. K. Nath and M.M.A. Mondal: Morphological characterization and assessment of genetic variability, character association and divergence in soybean mutants. The Scientific World J., p. 12. Article ID 968796 (2014).

Mazid, M.S., M.Y. Rafii, M.M. Hanafi, H.A. Rahim, M. Shabanimofrad and M.A. Latif: Agro-morphological characterization and assessment of variability, heritability, genetic advance and divergence in bacterial blight resistant rice genotypes. South African J. Bot., 86, 15-22 (2013)

Mishra, A.C., R.V. Singh and H.H. Ram : Studies on genetic divergence in capsicum (Capsicum annuum L.) in Uttaranchal. Capsicum and Egg Plant Newsletter, 23, 45-48(2004).

Nahak, S. C., A. Nandi, G.S. Shahu, P. Thripathy, S. Das, A. Mohanty and S. R. Pradhan: Assessment of genetic diversity in different chilli (Capsicum annum L.) genotype. Int. Curr. Micrbiol. App. Sci., 7,
634-639(2018)

Prasat, D., V. Ponnuswami and V. Murlidharan : Evaluation of chilli (Capsicum spp.) germplasm for extractable colour and pungency. Indian J. Genet., 67, 97-98(2007).

Rahman, M.M. and M.A.Z Munsur Al: Genetic divergence analysis of lime. J. Bangladesh Agril. Univ., 7, 33-37 (2009).

Raihana, R., M.Y. Rafii, M.M. Yosoff, S.I. Isail, G. Miyah and M. Usman: Genetic diversity analysis of selected Capsicum annum genotypes based on morphological and yield characteristics and their biochemical properties. J. Sci. Food Agric., 99, 269-280 (2019)

Rao, C.R.: Advanced Statistical Methods in Biometrics Research. John Wiley and Sons, New York, pp. 357 - 369 (1952).

Rhodes,A.M. and F.W. Martin: Multivariate studies of variation of varieties in yams (D. alata L.). J.Am. Soc. Hort. Sci., 97, 685-688(1972).

Roy, S., M.A. Islam, A. Sarkar, M.A. MaliK, M.Y. Rafi and M.R. Ismail: Determination of genetic diversity in lentil germplasm based on quality traits. Aust. J. Crop Sci., 7, 14-21 (2013).

Saleem, N., N.U. Zahida and S.I. Khan : Survey on use of synthetic food colours in food sample procured from different educational institutes of Karachi city. Trop. Life Sci., 3, 1-7 (2013).

Samsuddin, A.K.: Genetic diversity in relation to heterosis and combining analysis in spring wheat. Theo. Appl. Genet., 70, 306 $308(1985)$.

Shalini, M., S. Sharma, M.M. Gupta and K. Sushi : Evaluation of an Indian germplasm collection of the medicinal plant Bacopa monnieri (L.). Pennell by use of multivariated approaches. Euphytica, 133, 255$265(2003)$

Sharma, A.K., S.P. Singh and M.K. Sharma: Genetic variability heritability and character association in pea (Pisum sativum. L). Crop Res., 39, 31-41 (2003).

Singh, P.K., A. Kumar and A. Istiyaq : Corrilation and path coefficient analysis in yield contributing characters in chilli. Int. J. Plant Sci., 4 $104-111$ (2014).

Singh, R.K. and B.D. Choudhry: Diametrical Methods in Quantitative Genetic Analysis. Kalyani Publishers, New Delhi, p. 318 (1985).

Singh, S.R., N. Ahmed, S. Lal, S.A. Ganaie, M. Amin, N. Jan and A. Amin: Determination of genetic diversity in onion (Allium cepa L.) by multivariate analysis under long day conditions. Afri. J. Agric. Res., 8.5599-5606 (2013b).

Singh, S. R., S. Lal, N. Ahmed, K.K. Srivastava, D. Kumar, N. Jan, A. Amin and A.R. Malik: Determination of genetic diversity in strawberry (Fragaria $x$ ananassa) using the principal component analysis (PCA) and single linkage cluster analysis (SLCA). Afri. J. Biotech., 12,3474-3482(2013a).

Sneath, P.H.A. and R. Sokal : Numerical Taxonomy. W.H. Freeman, San Francisco, p. 573 (1973)

Steel, R.G. and R.H. Torie: Principles and Procedure of Statistics. $2^{\text {no }}$ Edn., M.C. Graw-Hill, Inc. New York (1980).

Tasso, Y., R.K. Dubey, V. Singh and G. Upadhyay : Genetic diversity in chilli (Capsicum annuum L.) genotypes of India based on morphochemical traits. Aust. J. Crop Sci., 8, 97-102 (2014).

Udachappa, U.P., S. Tirakannanavar, R.C. Jagdeesha, V. D. Gasti and N. Sandhyarani: Analysis of genetic divergence in chilli (Capsicum annum L.) genotypes. Int. J. Pure App. Biosci., 5, 503-508 (2017)

Woodbury, E. J.: Extractable colour of capsicum and oleoresin paprika. J. A.O.A.C., 60, 1-4(1997). 